\title{
Heat Capacity Study on the Evaluation of Uranium Nitride Using Einstein-Debye Approximation
}

\author{
Ebru Çopuroğlu \\ Department of Physics, Faculty of Arts and Sciences, Gaziosmanpaşa University, Tokat, Turkey \\ e mail: ebrucopuroglu@gmail.com
}

geliş tarihi ; 31.05.2016 kabul tarihi; 21.11.2016

Keywords

Heat Capacity; Einstein-Debye

Approximation; Nuclear Fuels

\section{Abstract}

We have proposed an alternative evaluation procedure for calculating specific heat capacity of Uranium Nitride nuclear fuel. The calculation results have been obtained by the use of Einstein-Debye approach. The proposed method is valid for all temperature values. This method can be easily applied to the other nuclear fuels to determine the other thermophysical properties.

\section{Einstein-Debye Yaklaşımı Kullanılarak Uranyum Nitrit' in Isı Kapasitesinin Değerlendirilmesi Üzerine Çalışma}

\author{
Anahtar Kelimeler \\ Isı Kapasitesi; Einstein-Debye \\ Yaklaşımı; Nükleer Yakıtlar
}

\begin{abstract}
Özet
Bu çalışmada alternatif nükleer yakıt olan Uranyum Nitrit' in Isı kapasitesinin hesaplanması için bir değerlendirme yöntemi ileri sürülmüştür. Hesaplama sonuçları Einstein-Debye yaklaşımı kullanılarak elde edilmiştir. Verilen yöntem sıcaklığın tüm aralıkları için geçerlidir. Bu yöntem diğer nükleer yakıtların termofiziksel özelliklerinin belirlenmesinde kolaylıkla uygulanabilr.
\end{abstract}

\section{Introduction}

Determining thermophysical properties of nuclear fuels is still one of the most challenging problems in nuclear physics and material sciences (Peng and Grimvall, 1994; Hoch and Vernadakis, 1976; Ronchi, 2007; Fink, 2000; Carbajo et. Al., 2001; Kang et. al., 2006; Yun and Oppeneer, 2011; Koç, et. al., 2011; Kurosaki et. al., 2001; Lemehov et. al., 2003; White and Nelson, 2013). It is well known that finding safer nuclear fuels to prevent tragic accidents is very important associated with the design of nuclear reactors. Common used nuclear fuel is the Uranium fuel which is not appropriate to the new generation reactors. Because of the thermal advantages, the Uranium Nitride (UN) fuels have been proposed and used as safer fuels in reactor designs (Szpunar and Szpunar, 2014; Pioro et al, 2008). From this point of view new researches on these alternative fuels can be seen as more attractive.

It is clear that one of the most exciting thermal properties of fuels is the heat capacity evaluation. In literature there are many experimental, numerical and theoretical methods to evaluate heat capacities of atoms and molecules (Mamedov, 2014; Kang et. al., 2006; Yun and Oppeneer, 2011; Koç, et. al., 2011; Kurosaki et. al., 2001; Lemehov et. al., 2003; White and Nelson, 2013; Grimvall, 1999). But it is necessary to be able to calculate the heat capacity of all materials without any restrictions. As an example, some 
calculation procedures of heat capacity calculations are not valid for all temperature ranges. One of the most used methods in literature is the Einstein-Debye approach (Cankurtaran \& Askerov, 1996; Askerov and Cankurtaran, 1994; Landau and Lifshits, 1980; Guseinov and Mamedov, 2007). Notice that the Einstein-Debye approach is important to solve many problems occurring in thermodynamics and material sciences without any restrictions.

For this purpose we have evaluated the heat capacity of UN fuel by the use of EinsteinDebye approach. By comparing the numerical integration data, the obtained results show that our evaluation method gives reliable computational efficiency. Also obtained formula is valid for all temperature values from low to melting temperatures.

\section{Metarial and Method}

By using Einstein-Debye approach the specific heat capacity at constant volume formula can be written as (Landau and Lifshits, 1980; Cankurtaran and Askerov, 1996):

$$
C_{V}=3 N_{A} k_{B} M\left(\frac{\theta_{D}}{T}, \frac{\theta_{E}}{T}\right) \text {, }
$$

here $k_{B}$ is the Boltzman constant, $N_{A}$ is the Avagadro number, $T$ is the absolute temperature, $\theta_{D}$ is the Debye temperature, $\theta_{E}$ is the Einstein temperature. The function $M\left(\frac{\theta_{D}}{T}, \frac{\theta_{E}}{T}\right)$ can be defined following as:

$$
M\left(\frac{\theta_{D}}{T}, \frac{\theta_{E}}{T}\right)=L_{V}\left(\frac{\theta_{D}}{T}\right)+(s-1) A\left(\frac{\theta_{E}}{T}\right) .
$$

Where, $L_{V}\left(\frac{\theta_{D}}{T}\right)$ is the isochoric heat function and $s$ is the number of atoms in one crystalline lattice point. For the case of $n$ dimensional crystalline, the $L_{V}\left(\frac{\theta_{D}}{T}\right)$ function is expressed by (Cankurtaran and Askerov, 1996):

$$
L_{V}\left(\frac{\theta_{D}}{T}\right)=n\left(\frac{T}{\theta_{D}}\right)^{n} \int_{0}^{\frac{\theta_{D}}{T}} \frac{t^{n+1} e^{t} d t}{\left(e^{t}-1\right)^{2}} .
$$

By considering $n$-dimensional Debye functions we can write the isohoric heat function $L_{V}\left(\frac{\theta_{D}}{T}\right)$ as :

$$
\begin{aligned}
& L_{V}\left(\frac{\theta_{D}}{T}\right)= \\
& (n+1) D_{n}\left(1, \frac{\theta_{D}}{T}\right)-\frac{\theta_{D}}{T} \frac{n}{e^{\frac{\theta_{D}}{T}}-1} .
\end{aligned}
$$

For simple metals and alloys, $n$ is taken values from 3 to 5. The quantities $D_{n}(\beta, x)$ in Eq. (4) are the $n$-dimensional Debye functions defined as:

$$
D_{n}(\beta, \mathrm{x})=\frac{n}{x^{n}} \int_{0}^{x} \frac{t^{n}}{\left(e^{t}-1\right)^{\beta}} d t .
$$

The quantity $A\left(\frac{\theta_{E}}{T}\right)$ occurring in Eq. (2) is the Einstein function and can be formulated by the following form (Cankurtaran and Askerov, 1996):

$$
\begin{aligned}
A\left(\frac{\theta_{E}}{T}\right) & =\left(\frac{\theta_{E}}{T}\right)^{2} \frac{e^{\frac{\theta_{E}}{T}}}{\left(e^{\frac{\theta_{E}}{T}}-1\right)^{2}} \\
& =\left[\frac{\theta_{E}}{2 T} \frac{1}{\sinh \left(\frac{\theta_{E}}{2 T}\right)}\right]^{2}
\end{aligned}
$$

It is clear that for the accurate computation of the heat capacity of materials, the evaluation procedure of integer and noninteger $n$-dimensional Debye functions has vital role. The analytically relation for the $n$ dimensional Debye function is given by ( Guseinov and Mamedov, 2007):

$$
\begin{aligned}
& D_{n}(\beta, x)=\frac{n}{x^{n}} \lim _{N \rightarrow \infty} \sum_{i=0}^{N}(-1)^{i} F_{i}(-\beta) \\
& \times \frac{\gamma(n+1,(i+\beta) x)}{(i+\beta)^{n+1}}
\end{aligned}
$$


where the quantity $N$ is the upper limit of summation. Also, the quantities $\gamma(n+1,(i+\beta) x)$ and $F_{i}(-\beta)$ are the well known incomplete gamma functions and binomial coefficients and can be determined as, respectively (Gradshteyn and Ryzhik, 1980):

$$
\begin{aligned}
& F_{m}(n)= \\
& \begin{cases}\frac{n(n-1) \ldots(n-m+1)}{m !} & \text { for integer } n \\
\frac{(-1)^{m} \Gamma(m-n)}{m ! \Gamma(-n)} & \text { for noninteger } n\end{cases}
\end{aligned}
$$

and

$$
\gamma(\alpha, y)=\int_{0}^{y} t^{\alpha-1} e^{-t} d t
$$

In literature, there are several useful methods for the exact definition of the incomplete gamma function (Guseinov and Mamedov, 2004).

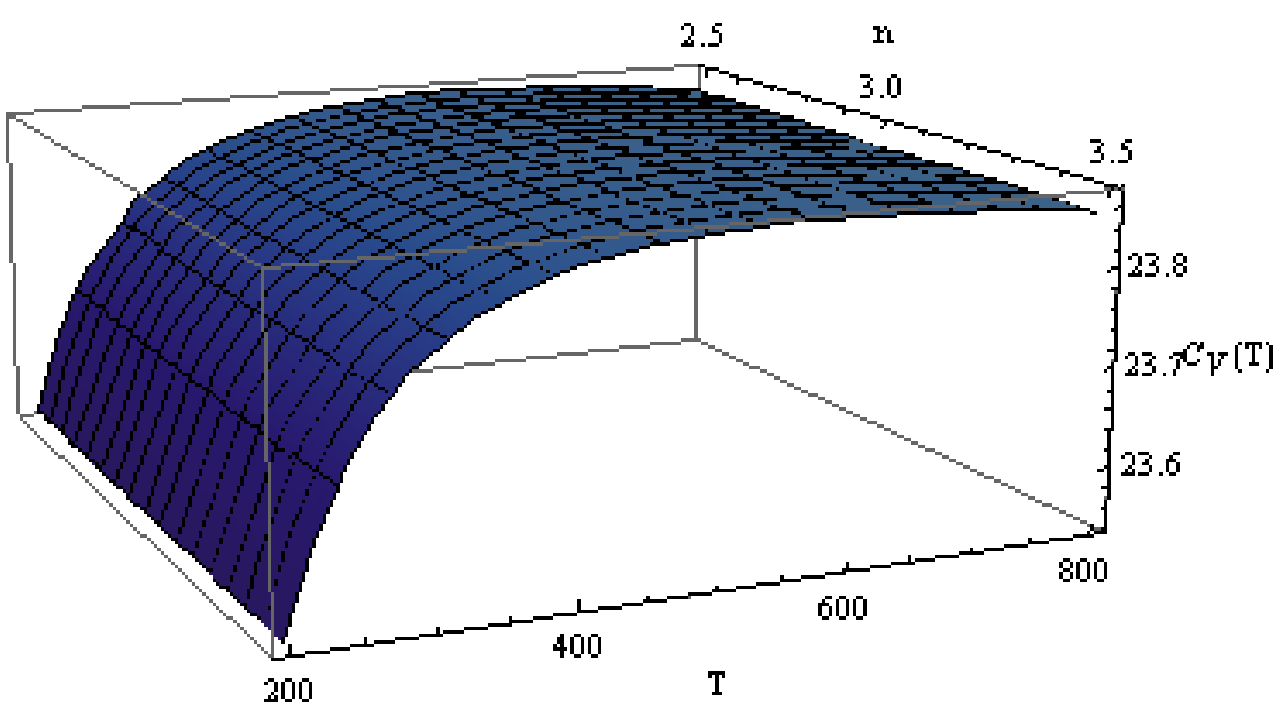

Figure 2. 3D figure for the heat capacity of Uranium nitride at constant volume with respect to the temperature (T) and $n$ parameter.

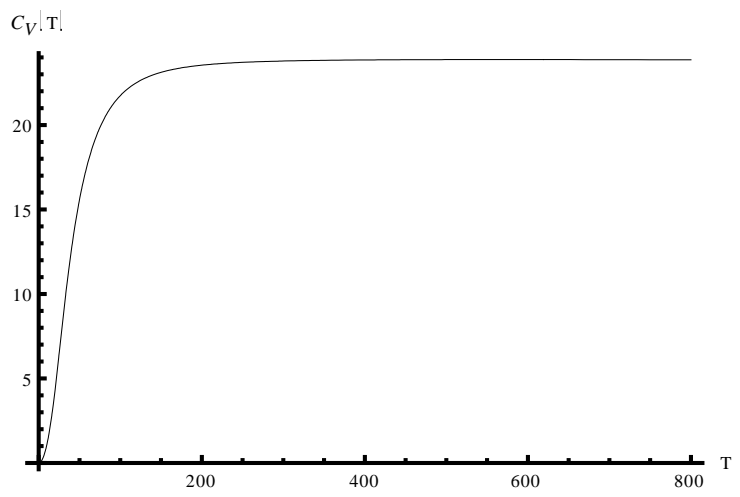

Figure 1. Uranium nitride specific heat capacity at constant volume as a function of temperature

\section{Numerical results and discussion}

In this paper, an analytical evaluation procedure for calculating heat capacity of UN nuclear fuel has been presented. A computer program has been constructed for the evaluation of specific heat capacity at constant volume by the use of Mathematica programming language. Taking into account Einstein-Debye approach and $n$-dimensional Debye function, the specific heat at constant volume has been plotted in Fig. (1) with respect to the temperature $T$. Also, for the integer and non-integer values of $n$ in ranges (2.5-3.5), we give the calculation results of heat capacity in Fig.2. For all calculations the Debye and Einstein temperatures $\theta_{D}$ and $\theta_{E}$ is taken about $325 K$ and $534 K$, respectively. In literature, the integer values of parameter $n$ 
for nuclear fuel samples are reported in range from 3 to 5. Using Eq. (1), we can calculate Debye functions of any integer and noninteger values of $n$.

\section{Conclusion}

As a conclusion, by the use of Einstein- Debye approach we calculated the heat capacity of

\section{References}

Askerov, B.M., Cankurtaran, M., 1994, Isobaric specific-heat and thermal expansion of solid in the Debye approximation. Phys. Stat. Sol. B,

185, 341-348.

Carbajo, J. J., Yoder, G. L., Popov, S. G., Ivanov, V. K., 2001, A review of the thermophysical properties of $\mathrm{MOX}$ and $\mathrm{UO}_{2}$ fuels. J. Nucl. Mater. 299, 181-198.

Cankurtaran, M., Askerov, V., 1996, Equation of state, isobaric specific heat, and thermal expansion of solids with polyatomic basis in the Einstein-Debye approximation. Phys. Stat. Sol. B, 194, 499-507.

Fink, J. K., 2000, Thermophysical properties of uranium dioxide. J. Nucl. Mater. 279, 1-18.

Guseinov, I.I., Mamedov, B.A., 2007, Calculation of integer and noninteger $n$-dimensional debye functions using binomial coefficients and incomplete gamma functions. Int. J. Thermophys 28, 1420-1426.

Guseinov, I.I., Mamedov, B.A., 2004, Evaluation of incomplete gamma functions using downward recursion and analytical relations. J. Math. Chem. 36, 341-346.

Grimvall G., 1999, Thermophysical properties of materials, Elsevier Science B.V., Amsterdam.

Gradshteyn, I.S., Ryzhik, I.M., 1980, Tables of Integrals, Series and Products, Academic Press, New York.

Hoch, M., Vernadakis, T., 1976, Thermodynamic properties of solid and liquid metals and ceramics. High Temp.-High Press. 8, 241-246.

Kurosaki, K., Yamada, K., Uno, M., Yamanaka, S., Yamamoto, K., Namekowa, T., 2001, Molecular dynamics study of mixed oxide fuel.
UN nuclear fuel in the range of temperatures from $0 \mathrm{~K}$ to $800 \mathrm{~K}$. As can be seen from the formula and obtained results, given method is completely general and free of any restrictions on its applications. By considering the efficiency, this study can be useful in many material applications especially in designing nuclear reactors safely.

J. Nucl. Mater. 294, 160-167.

Kang, K. H., Song, K. C., Yang, M. S., Lee, S. H., Ko, J. B., Kim, S. W., 2006, Thermophysical properties of multi-walled carbon nanotubereinforced polypropylene composites. Int. J. Thermophys. 27, 152-160.

Koç, H., Eser, E., Mamedov, B.A., 2011, Calculation of heat capacity of the nuclear fuels $\mathrm{UO}_{2}$ and $\mathrm{NpO}_{2}$ using integer and non-integer $n$ dimensional Debye functions. Nucl. Engin. Design, 241, 3678-3682.

Lemehov, S.E., Sobolev, V., Van Uffelen, P., 2003, Modelling thermal conductivity and selfirradiation effects in mixed oxide fuels. J. Nucl. Mater. 320, 66-76.

Landau, L. D., Lifshits, E.M., 1980, Statistical Physics, Pergamon Press, London.

Mamedov B.A., 2014, Accurate analytical evaluation of heat capacity of nuclear fuels using Einstein-Debye approximation, Nuclear Engineering and Design, 276, 124.

Peng, S, Grimvall, G., 1994, Heat capacity of actinide dioxides. J. Nucl. Mater. 210, 115122.

Pioro I.L., Khan M., Hopps V. et al., 2008, Journal of Power and Energy Systems, 2, 874.

Ronchi, C., 2007,Thermophysical properties affecting safety and performance of nuclear fuel. High Temperature 45, 552-571.

Szpunar B. , Szpunar J.A., 2014, International Journal of Nuclear Energy, 2014, 7.

White, J.T., Nelson, A.T., 2013, Thermal conductivity of $\mathrm{UO}_{2+x}$ and $\mathrm{U}_{4} \mathrm{O}_{9-y}$. J. Nucl. Mater. 443, 342-350.

Yun, Y., Oppeneer, P. M., 2011, First-principles design of next-generation nuclear fuels Mater. Res. Soc. (MRS)-Bulletin 36, 178-184. 